\title{
RESISTANCE OF MORTARS WITH GYPSUM, LIME AND COMPOSITE BINDERS AGAINST MOLDS
}

\author{
Jitka Krejsová*, MagdalÉna Doleželová \\ Czech Technical University in Prague, Faculty of Civil Engineering, \\ Department of Materials Engeneering and Chemistry, Thákurova 7, 16629 Prague, Czech Republic \\ * corresponding author: jitka.krejsova@fsv.cvut.cz
}

\begin{abstract}
Resistance of three mortars (the lime mortar, the gypsum mortar and the mortar with the composite binder) against molds was evaluated. Mortars were also compared according to their $\mathrm{pH}$, bulk density, strength and porosity. Experiments showed that the lime mortar has the best resistance against molds and the lowest bending and compressive strength. The mortar with the composite binder has better mold resistance and higher bending and compressive strength than the gypsum mortar.
\end{abstract}

KEYwords: Calcium sulfate dihydrate, gypsum, mold resistance, mortars, plasters.

\section{INTRODUCTION}

Gypsum is widely used material in building industry especially for production of gypsum plaster, plasterboard (drywall), gypsum blocks [1] and some composite materials. Gypsum plaster often contains filler, which can improve thermal insulation properties, reduce binder consumption, reduce volume changes during exposure to high temperatures [2] etc. In terms of composition, gypsum plaster with filler is actually gypsum mortar (it contains calcium sulfate hemihydrate based binder, fine aggregate and water). Production of gypsum based products is more environmentally friendly [3] and faster than production of cement based products. However, use of gypsum products is significantly limited by their low moisture resistance. According to recent research [4, moisture resistance can be improved by adding lime and silica fume to gypsum binder where lime acts as an alkaline activator of the pozzolan reaction. Mortar with such binder is being developed and researched [5], but some of its properties are still unknown, for example mold resistance which is important but often neglected property. Molds belong to microorganisms, that commonly appear on inner and outer surfaces of building structures and can cause sick building syndrome (people in a building feel ill from no apparent reason) and threaten human health 6. Molds also damage building materials by biodegradation (synergic process of chemical and physical biodegradation) [7. In general, gypsum based materials have worse mold resistance than cement based materials [8, [9] which corresponds with different $\mathrm{pH}$ of these materials. However, e.g. water content in materials and additives also play an important role [8]. That's why this paper is focused on the possibility of improving the mold resistance of gypsum mortat by adding lime and silica fume to the gypsum binder. Also pH, bulk density, strength and porosity of the lime mortar, the gypsum mortar and the mortar with the composite binder (gypsum, lime and silica fume) is tested and compared.

\section{MATERIALS}

The mortars were made of grey gypsum binder (Gypstrend s.r.o.), white hydrated lime (Vápenka Čertovy schody a.s.), silica fume (Stachesil S, Stachema), standardized sand (according to the ČSN EN 196-1 [10] standard) and water. Silica fume was used as a pozzolan additive and hydrated lime was added as an activator of the pozzolanic reaction. The compositions of the mortars are in 1 .

\section{Experimental Methods}

Sample preparation and testing. Squared samples of $30 \times 30 \times 3 \mathrm{~mm}$ size were prepared for mold growth testing. Prisms of $40 \times 40 \times 160 \mathrm{~mm}$ size were prepared for physical properties testing according to the ČSN EN 13454-2+A1 [11]. Dry components of binders were mixed, poured into water and placed in standardized automatic mixer. Sand was added after $30 \mathrm{~s}$ of mixing. Mixtures were put in moulds on $2-24$ hours and then they were put out of moulds and stored in laboratory conditions for at least 28 days. After that, experiment was divided into four modifications (as shown in Table 22) according to the type of sterilization and location of samples.

Mediums used in modification $\mathrm{A}, \mathrm{B}$, and $\mathrm{C}$ were following ( $\mathrm{D}$ was without medium):

- (CZ) Czapek-dox (commercial medium produced by Oxoid)

- (MIN) mineral medium (follow composition per l: 2 g $\mathrm{NaNO}_{3} ; 0.7 \mathrm{~g} \mathrm{KH}_{2} \mathrm{PO}_{4} ; 0.3 \mathrm{~g} \mathrm{~K} \mathrm{HPO}_{4} ; 0.5 \mathrm{~g}$ $\mathrm{MgSO}_{4} \cdot{ }_{7} \mathrm{H}_{2} \mathrm{O} ; 0.01 \mathrm{~g} \mathrm{FeSO}_{4} \cdot{ }_{7} \mathrm{H}_{2} \mathrm{O}$ ) according to the ČN EN ISO 846 [12].

Each sample was placed in the center of petri dish with medium. All squared samples and mediums were inoculated by spreading of physiological solution with four commonly occurring molds - Cladosporium cladosporioides, Asperigillus versicolor, Stachybotrys 


\begin{tabular}{|c|c|c|c|c|c|}
\hline Sample & $\begin{array}{c}\text { Calcined gypsum } \\
\text { [wt. \%] }\end{array}$ & Lime [wt. \%] & Silica Fume [wt. \%] & Sand [wt. \%] & Water/binder ratio [-] \\
\hline GM & 33 & - & - & 67 & 1 \\
LM & - & 3.3 & - & 67 & 1 \\
GLSM & 27 & 3.2 & 2.8 & 67 & 0.82 \\
\hline
\end{tabular}

TABle 1. Composition of mortars

\begin{tabular}{|l|l|l|}
\hline & Sample sterilization & Storage of inoculated samples \\
\hline A & - & on mediums in Petri dishes in biological thermostat \\
B & alcohol and UV radiation & on mediums in Petri dishes in biological thermostat \\
C & autoclaving & on mediums in Petri dishes in biological thermostat \\
D & - & $100 \% \mathrm{RH}$ in desiccator \\
\hline
\end{tabular}

TABle 2. Modifications of Experiment

chartum and Penicilium purpurogenum which are obtained from Czech collection of microorganism (CCM).

The microscope pictures of the molds are below $1 \mathrm{a}, 1 \mathrm{~b}$ - all pictures are in the same scale). The incubation was at $26{ }^{\circ} \mathrm{C}$ for three months. Rate of mold growth was monitored for 4 - 12 weeks every week as a cover of sample and halo effect around the sample. After the finishing of experiment the samples were evaluated by microscopy.

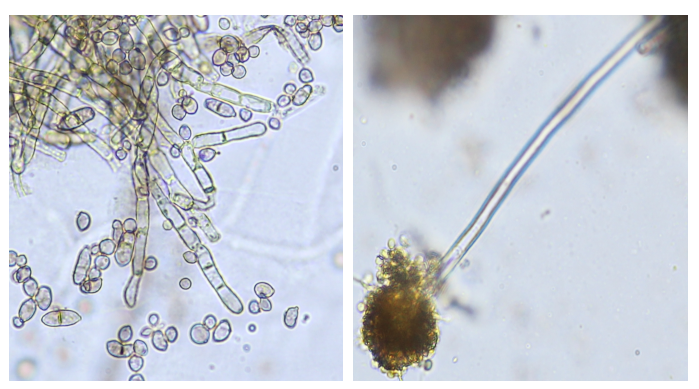

(a) Left - Cladosporium cladosporioides, right - Asperigillus versicolor.
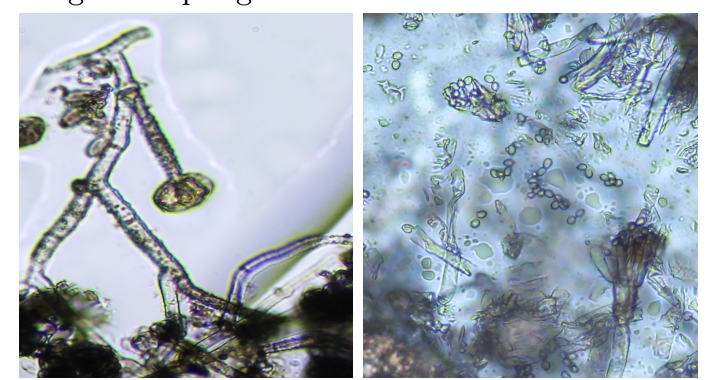

(b) Left - Stachybotrys chartum, right - Penicilium purpurogenum.

Figure 1. Microscope pictures

Samples were stored for 28 days in laboratory conditions. Their $\mathrm{pH}$ was determined by $\mathrm{pH}$ paper from dispersion of crushed samples in distilled water. Bulk density $\rho_{v}\left[\mathrm{~kg} / \mathrm{m}^{3}\right]$ was determined by gravimetric method on dried prismatic samples. Bending strength $f_{f}[\mathrm{MPa}]$ and compressive strength $f_{c}[\mathrm{MPa}]$ were determined using press FP 100 (VEB Industriewerk Ravenstein) in accordance with the CSN EN 13279-2 [13 on dried prismatic samples. Porosity and pore size distribution were determined using mercury intrusion porosimetry device Pascal $140+440$ (Thermo Scientific) on dried pieces of prismatic samples.

\section{Results}

Physical and chemical properties. Values of $\mathrm{pH}$ are summarized in table 3 As expected, the gypsum mortar has the lowest $\mathrm{pH}$. Bulk densities of all mortars are similar, as can be seen in table 3. Bending and compressive strength of mortars are in 2. The mortar with the composite binder (GLSM) has almost three times higher compressive strength than the lime mor$\operatorname{tar}(\mathrm{LM})$ and more than one and half times higher compressive strength than the gypsum mortar (GM).

\begin{tabular}{|l|c|c|c|}
\hline Sample & $\mathrm{pH}$ & Bulk density $\left[\mathrm{kg} / \mathrm{m}^{3}\right]$ & Porosity [-] \\
\hline GM & 6 & 1458 & 42.5 \\
LM & 10 & 1642 & 32.6 \\
GLSM & 11 & 1581 & 38.5 \\
\hline
\end{tabular}

TABLE 3. Physical and chemical properties of mortars.

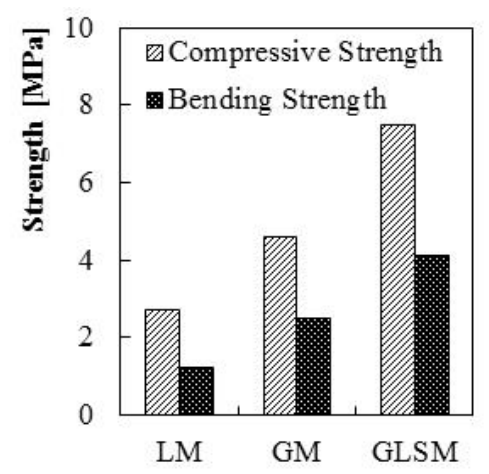

Figure 2. Bending and compressive strength.

Total porosity of all mortars is similar (see table 3). The gypsum mortar has primarily pores of size about $1 \mu \mathrm{m} 3$ The mortar with the composite binder has these pores partially filled by CSH-phases formed during the pozzolanic reaction [5]. Size of pores in the lime mortar is between $10^{-8} \mathrm{~m}$ and $10^{-4} \mathrm{~m}$. Therefore, all three mortars have mainly capillary pores 


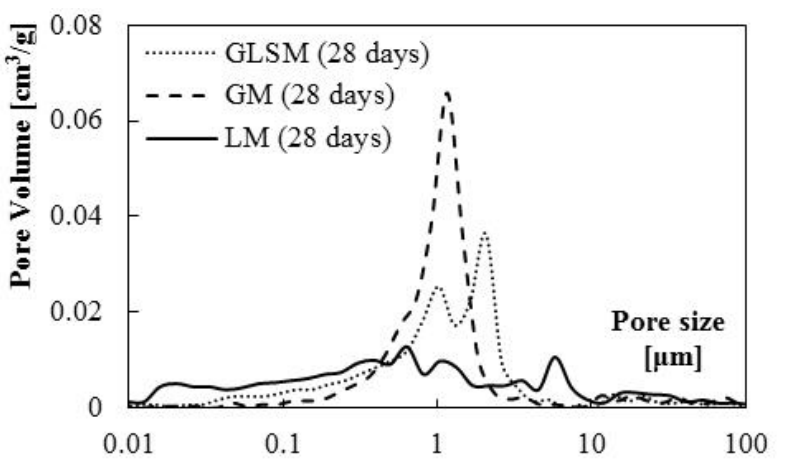

Figure 3. Pore size distribution.

$\left(10^{-9}-10^{-3} \mathrm{~m}\right)$. In these capillary pores, water movement is induced by surface tension (capillary forces) and that is why rising dump may occur in these materials. Moisture significantly support mold growth and therefore, moisture transport properties of materials are important. It can be expected, that moisture transport properties of the three mortars differs due to the different pore size distribution.

Resistance against molds. Mortars resistance against molds was evaluated using the five point scale, where: 0 - no molds, 1 - mold growth is visible under microscope, 2 - molds cover less than $25 \%$ of sample surface, 3 - molds cover 25 - $50 \%$ of sample surface, 4 - molds cover more than $50 \%$ of sample surface, 5 molds completely cover sample surface. Mean results are in table 4 Mold growth on different samples made of same material and same modification was similar.

Results show that molds grow more and faster on samples with lower $\mathrm{pH}$ (about 6), respectively on samples without lime, which corresponds to literature [9]. Results also show higher resistance to mold growth of unsterilized samples A. It could be caused by the fact that some microorganisms that decelerate mold growth were destroyed by sterilization. On the lime mortar (LM), mold growth did not appear during the experiment and so called halo effect (see 5 ) occurred around samples A and B. It means that medium near sample was influenced by the sample. Leaches (probably $\mathrm{Ca}(\mathrm{OH})_{2}$ leaches) formed around the sample and molds did not grow in this inhibition zone (see 5). The lime mortar (LM) can be classified as biocidal (for about four weeks) due to this phenomenon. Halo effect did not occur around autoclaved samples C. It was probably caused by the release of free $\mathrm{Ca}_{2}^{+}$ions during autoclaving. Halo effect also appeared around the mortar with the composite binder (GLSM) probably due to its $\mathrm{Ca}(\mathrm{OH})_{2}$ contain. This mortar sustains the biocidal properties for four days. Microorganisms probably created the appropriate growth environment for molds during this time. Mold growth occurred after one week on samples on the Czapek-Dox medium. Molds did not grow on samples on the mineral medium. Fast mold growth and no halo effect were observed on the gypsum mortar (GM) in accordance with literature 14. Molds were observed few weeks after inoculation even on surfaces of the samples on mineral medium. This mortar has therefore worse resistance against molds than the mortar with the composite binder. However, mold growth on all tested mortars is caused by the presence of medium in the pores of the samples. It is proved by the modification D. All samples in modification D were monitored for 12 weeks and mold growth was not observed. After 12 weeks, some molds were observed under microscope. These molds were probably spread on sample surface during inoculation at the beginning of experiment and they have not grown since that. It means that tested mortars do not have enough essential nutrients for mold growth. Results show that relatively low content of lime and silica fume in gypsum binder significantly improved resistance of mortar against molds.

\section{Conclusion}

Resistance against molds, $\mathrm{pH}$, bulk density, strength and porosity of the lime mortar, the gypsum mortar and the mortar with the composite binder (gypsum, lime and silica fume) were investigated. Experimental results showed that:

- the mortar with the composite binder has almost three times higher bending and compressive strength than the lime mortar and about one and half times higher bending and compressive strength than the gypsum mortar (GM);

- the gypsum mortar has the lowest $\mathrm{pH}$ value;

- pore size distribution of the mortars differs while their total porosity and bulk density are similar,

- the tested mortars do not have enough essential nutrients for mold growth (tested time was 12 weeks);

- molds grow on the gypsum mortar and on the mortar with the composite binder if nutrients are added,

- molds do not grow up on the lime mortar (during 6 weeks); the lime mortar has the best resistance against molds and the gypsum mortar has the worst resistance against molds,

- inhibition zone occurred around the lime mortar and the mortar with the composite binder and these mortars can be classified as biocidal (for 4 weeks the lime mortar, resp. 4 days - the mortar with the composite binder).

The mortar with the composite binder has better mold resistance and higher bending and compressive strength than the gypsum mortar. The mortar with the composite binder is therefore more suitable for use in practice, e.g. as a plaster in building structures. Future research might be focused on mold resistance improving for example by adding nanoparticles [8].

\section{ACKNOWLEDGEMENTS}

This research has been financially supported by the project SGS 16/199/OHK1/3T/11. The experiments were performed in cooperation with Microbiological and Chemical 


\begin{tabular}{|c|c|c|c|c|c|c|c|c|c|c|c|c|c|c|}
\hline Sample & Modification & \multicolumn{1}{|c|}{ Time [week] (medium CZ) } & \multicolumn{1}{|c|}{ Time [week] (medium MIN) } \\
\hline & & 1 & 2 & 3 & 4 & 5 & 6 & 1 & 2 & 3 & 4 & 5 & 6 \\
\hline \multirow{5}{*}{ GM } & A & 2 & 2 & 2 & 2 & - & - & 0 & 0 & 0 & 0 & - & - \\
& $\mathrm{B}$ & 3 & 4 & 4 & 4 & 4 & 4 & 0 & 0 & 0 & 2 & 2 & 2 \\
& $\mathrm{C}$ & 4 & 4 & 4 & 4 & 4 & - & 0 & 0 & 0 & 0 & 0.5 & - \\
& $\mathrm{D}$ & - & - & - & - & - & - & - & - & - & - & - & - \\
\hline \multirow{5}{*}{ LM } & $\mathrm{A}$ & 0 & 0 & 0 & 0 & - & - & 0 & 0 & 0 & 0 & - & - \\
& $\mathrm{B}$ & 0 & 0 & 0 & 0 & 0 & 0 & 0 & 0 & 0 & 0 & 0 & 0 \\
& $\mathrm{C}$ & 0 & 0 & 0 & 0 & 0 & - & 0 & 0 & 0 & 0 & 0 & - \\
& $\mathrm{D}$ & - & - & - & - & - & - & - & - & - & - & - & - \\
\hline \multirow{5}{*}{ GLSM } & $\mathrm{A}$ & 2 & 2 & 2 & 2 & - & - & 0 & 0 & 0 & 0 & - & - \\
& $\mathrm{B}$ & 0 & 2 & 3 & 3 & 3 & 3 & 0 & 0 & 0 & 0 & 0 & 0 \\
& $\mathrm{C}$ & 2 & 2 & 2 & 2 & 2 & - & 0 & 0 & 0 & 0 & 1 & - \\
& $\mathrm{D}$ & - & - & - & - & - & - & - & - & - & - & - & - \\
\hline
\end{tabular}

TABLE 4. Mold growth

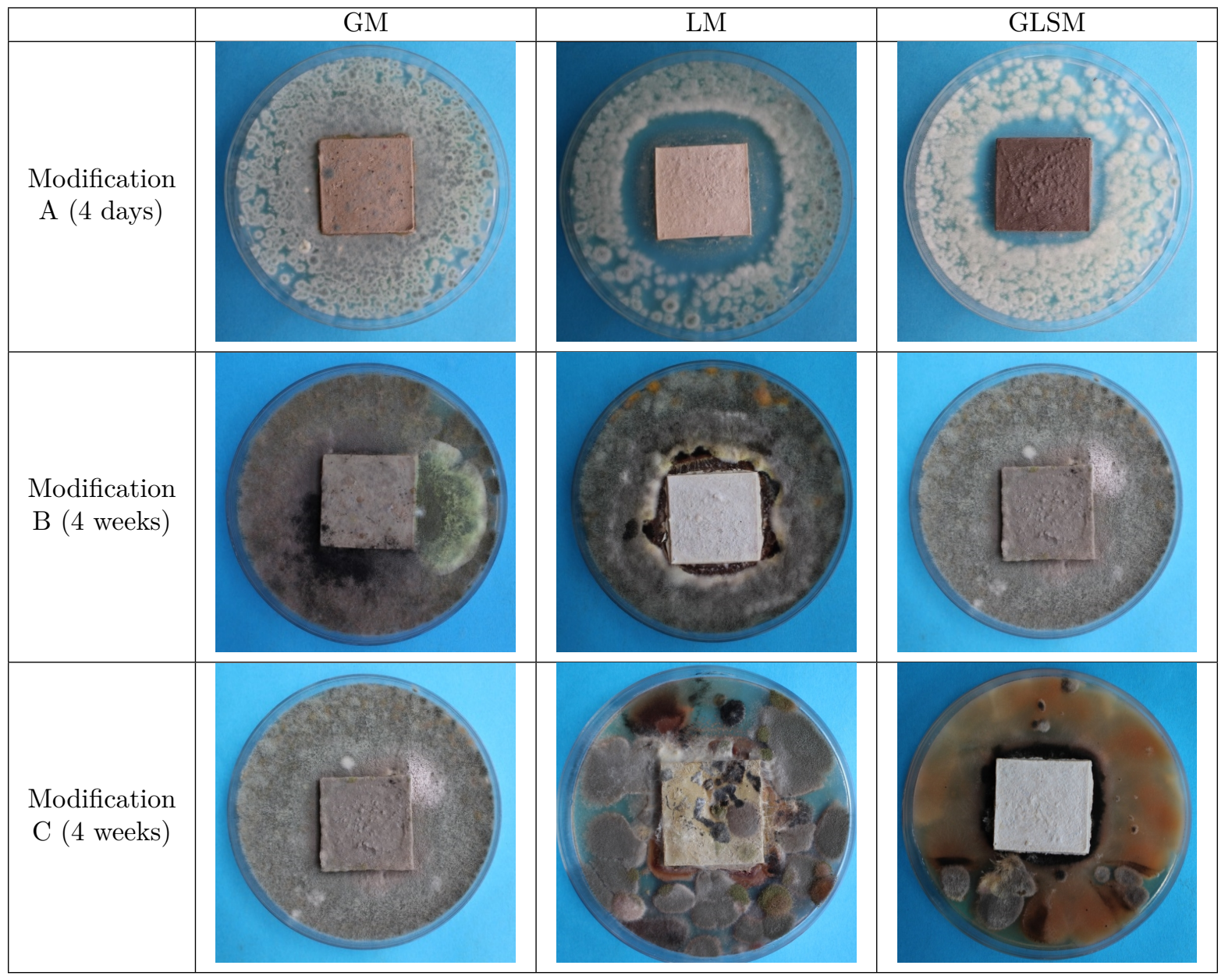

TABle 5. Inoculated Samples, Czapek-Dox Medium.

Laboratory, Department of Building Structures, Faculty of Civil Engineering, Czech Technical University, Prague, namely with Mgr. Pavla Ryparová, Ph.D. and Ivana Loušová.

\section{REFERENCES}

[1] Casado, Rodrigues. Construction technology of internal gypsum block partitioning, 2012. Brick and Block Masonry Conference.

[2] Doleželová, Scheinherrová, Krejsová, Vimmrov. Effect of high temperatures on gypsum-based composites. Construction and Building materials 168:82-90, 2018.

[3] J. Bakker, H. Brouwers. Mortar and concrete based on calcium sulphate binders. In Proceedings 16th Ibausil, International Conference on Building Materials (Internationale Baustofftagung), Weimar, 20-22 September 2006. FA Finger Institut für Baustoffkunde, 2006.

[4] M. Doleželová, A. Vimmrová. Moisture influence on compressive strength of ternary gypsum-based binders. 
In AIP Conference proceedings, vol. 1863, p. 290003. AIP Publishing, 2017.

[5] M. Doleželová, J. Pokorný, A. Vimmrová. Design of the ternary gypsum-based building composite with the help of simplex optimization, 2018. 2nd International Conference on Materials Design and Applications.

[6] P. Ryparová, Z. Rácová. The occurrence of mold in construction materials before inbuilt into new building and protection against this type of biodegradation, 2016.

[7] P. Ryparová, R. Wasserbauer, Z. Rácová. The Cause of Occurrence of Microorganisms in Civil Engineering and the Dangers Associated with their Growth, 2016. Procedia Engineering.

[8] Z. Rácová, P. Ryparová. Silver inhibition effect of nanoparticles on specific mold group growth, 2015. NANCON.
[9] Méndez, Pérez, Aguilar, et al. Red pigment production by penicillium purpurogenum gh2 is influenced by ph and temperature, 2011.

[10] ČSN EN 196-1. Methods of testing cement. determination of strength., 2005. Prague.

[11] ČSN EN 13454-2+A1. Binders, composite binders and factory made mixtures for floor screeds based on calcium sulfate. test methods, 2008.

[12] ČSN EN ISO 846. Plastics - Evaluation of the action of microorganisms, 1998.

[13] ČSN EN 13279-2. Gypsum binders and gypsum plasters. Test Methods, 2014.

[14] S. M. Nieminen, R. Kärki, S. Auriola, et al. Isolation and identification of Aspergillus fumigatus mycotoxins on growth medium and some building materials. Applied and environmental microbiology 68(10):4871-4875, 2002. 